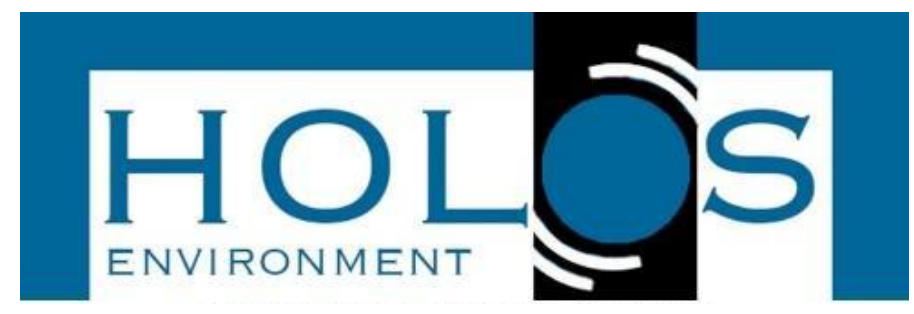

\title{
APLICAÇÃO DE INDICADORES DO TURISMO SUSTENTÁVEL EM UM BALNEÁRIO EM ÁREA DE CERRADO NO MUNICÍPIO DE COXIM - MS
}

\section{APPLICATION OF SUSTAINABLE TOURISM INDICATORS IN A BATHHOUSE IN A CERRADO AREA IN THE MUNICIPALITY OF COXIM - MS}

\author{
Mylena dos Santos ${ }^{1}$; Poliana Ferreira da Costa ${ }^{1}$; \\ Eriquedima Costa de Oliveira dos Santos ${ }^{1}$
}

Artigo recebido em: 11/03/2020 e aceito para publicação em: 04/07/2020.

DOI: http:/dx.doi.org/10.14295/holos.v20i3.12380

Resumo: O turismo tem importante papel no desenvolvimento econômico e o Brasil apresenta alto potencial para esta atividade. $\mathrm{O}$ ecoturismo surge como uma alternativa sustentável frente as atividades econômicas comumente utilizadas, e indicadores ambientais podem ser aplicados para identificar e mensurar variações em um ou mais elementos de uma atividade. Este trabalho tem como objetivo principal aplicar indicadores ambientais, sociais e econômicos em uma atividade de ecoturismo em uma pousada e balneário no Município de Coxim, MS, a fim de analisar os prós e contras dessa atividade. Para a construção dos indicadores empregados neste trabalho foi realizado um levantamento bibliográfico acerca dos principais indicadores de impactos ambientais, sociais e econômicos do ecoturismo existentes. Também foram realizadas visitas técnicas para análise e aplicação dos indicadores no local de estudo, em maio de 2019. Foram aplicados um total de 29 indicadores de sustentabilidade (17 indicadores na dimensão ambiental, 6 indicadores na dimensão social e 6 indicadores para a dimensão econômica). Foi possível concluir que a atividade ecoturística utiliza métodos de baixo impacto ambiental e induz o desenvolvimento econômico e social.

Palavras-chave: Ecoturismo. Ambienta. Econômico. Social. Sustentabilidade.

\begin{abstract}
Tourism plays an important role in economic development and Brazil has a high potential for this activity. Ecotourism appears as a sustainable alternative to commonly used economic activities, and environmental indicators can be applied to identify and measure variations in one or more elements of an activity. This work has as main objective to apply environmental, social and economic indicators in an ecotourism activity in an inn and spa in the Municipality of Coxim, MS, in order to analyze the pros and cons of this activity. For the construction of the indicators used in this work, a bibliographical survey was carried out on the main indicators of environmental, social and economic impacts of ecotourism. Technical visits were also carried out to analyze and apply the indicators at the study site, in May 2019. A total of 25 sustainability indicators were applied (17 indicators in the environmental dimension, 4 indicators in the social dimension and 4 indicators in the economic dimension). It was possible to conclude that ecotourism activity uses methods with low environmental impact and induces economic and social development.
\end{abstract}

Keywords: Ecotourism. Environmental. Economic, Social. Sustainability.

\footnotetext{
1 Universidade Estadual do Mato Grosso do Sul - (UEMS), Coxim, MS. E-mails: (mylenasantospg11@hotmail.com, polianacostagestao@gmail.com, erikdma@gmail.com)
} 


\section{INTRODUÇÃO}

Como uma ação de deslocamento temporário e voluntário de pessoas para locais fora de sua cidade, o turismo se destaca como atividade socioeconômica de lazer que emprega infraestrutura de serviços, equipamentos, aspectos como motivação humana e inter-relação cultural e ecológica entre pessoas que constituem um negócio (BRAGA, 2007). Como uma representativa atividade no setor econômico brasileiro esse ramo de atividade gera renda e emprego, incentivo ao desenvolvimento tecnológico, preservação do patrimônio histórico nacional e do meio ambiente (MOTA, 2001; OLIVEIRA, 2008).

Dentro de uma das segmentações do setor turístico encontramos o ecoturismo, que de acordo com MMA (2010), é uma atividade que emprega a conservação ambiental, o desenvolvimento da comunidade local, princípios da sustentabilidade e o emprego de bases legais.

Rezende e Rezende (2005) destacam que essa atividade, como a maioria do setor econômico, pode trazer benefícios e malefícios em sua implantação e operação, sejam de origem econômica, social e ambiental. Essas implicações causadas pelo turismo podem ser definidas como impactos. Para a resolução desses impactos e a potencialização dos benefícios do turismo na região a serem implantados faz se necessário à sua identificação e análise para um eficiente manejo da atividade.

Entre alguns impactos positivos econômicos que podemos encontrar com a instalação e operação de uma atividade turística temos a geração de renda, emprego, impostos e receita e incentivos a investimentos em infraestrutura e mão-de-obra, em compensação temos como impactos negativos aumento de impostos territoriais, aumento do preço de bens e serviços e até segregação espacial (IGNARRA. 1999; TOFANI, 1999).

Já os impactos ambientais negativos causados pela atividade são: alteração na qualidade da água, solo e ar, supressão vegetal, compactação do solo, erosão e assoreamento de corpos hídricos, modificação do comportamento da fauna local, e outros (DUTRA et al., 2015). Ainda nesse contexto também encontramos alguns impactos negativos sociais como: alteração de valores culturais locais e modificação do modo de vida da população tradicional do local (OMT, 1998).

O turismo em algumas regiões é a fonte mais importante de emprego e renda, pois além de apresentar um cenário de ambientes naturais propicio para essa área, certas regiões propõem ações sustentáveis, que tem como objetivo a valorização e preservação dos patrimônios históricos e culturais que sofrem com a degradação ocasionada pelas 
atividades econômicas antrópicas comumente utilizadas. Dessa maneira, tal atividade, consegue através de um planejamento contínuo atender a relação entre turismo e meio ambiente (BENI, 2002; BRAGA, 2007).

Segundo Lacerda (2011), a sustentabilidade no turismo consiste em uma ferramenta que aponta os impactos provocados ao meio ambiente, e estabelece medidas preventivas ou corretivas quando necessário. Para a identificação desses impactos e de seu grau de magnitude e para a formulação de soluções de manejo eficientes podem ser aplicados nos locais de operação da atividade turística, indicadores de impactos ambientais, sociais e econômicos (DUTRA et al., 2015). Parris e Kates (2003) relatam que os indicadores podem ser usados para identificar e mensurar variações em um ou mais elementos de uma atividade. Estes são capazes de atender as informações importantes que podem promover a concepção dos problemas econômicos, sociais e ambientais, assim como garantir o conhecimento da população em estabelecer e conduzir políticas e projetos de desenvolvimento sustentável (REED, FRASER e DOUGILL, 2006).

Para van Bellen (2006), os sistemas de indicadores de sustentabilidade correspondem aos instrumentos que são adotados para estimar o nível do desenvolvimento sustentável de uma dada área ou de uma dada atividade econômica. O objetivo principal dos indicadores é o monitoramento de determinados processos em relação a uma meta ou padrão mínimo de desempenho estabelecido.

Para tanto, os indicadores de sustentabilidade se constituem uma importante ferramenta capaz de fornecer informações que auxiliem na elaboração do planejamento por aproximar os pesquisadores da realidade de determinada localidade (NUNES e MARTINS, 2019). O Sistema de Indicadores de Sustentabilidade do Desenvolvimento do Turismo SISDTur, é considerado como um dos modelos mais completos, visto que contempla as dimensões (econômico, social, ambiental, cultural, institucional e turística) da sustentabilidade, elaborado com o princípio de uma abordagem participativa, que envolve a comunidade local, bem como pontos de vista dos demais grupos envolvidos.

Desse modo este trabalho tem como objetivo principal aplicar indicadores ambientais, sociais e econômicos em uma atividade de ecoturismo em uma pousada no Município de Coxim, MS, a fim de analisar os prós e contras dessa atividade.

\section{METODOLOGIA}

Para a construção dos indicadores empregados neste trabalho foi realizado um 
levantamento bibliográfico acerca dos principais indicadores de impactos ambientais, sociais e econômicos do ecoturismo existentes. Desse modo, foram utilizados indicadores descritos nos trabalhos de Van Bellen (2006), Hanai (2009), Fadini et al. (2010), Ruschmann (2010), Dutra et al. (2015), Silva e Cândido (2016), Nunes e Martins (2019) e o Sistema de Indicadores de Sustentabilidade do Turismo (SISDTur), para a formulação de uma matriz de indicadores de sustentabilidade nas respectivas dimensões ambientais, sociais e econômicos, a fim de, avaliar a atividade turística proporcionando informações que contribuem para o seu monitoramento contínuo sob o olhar da sustentabilidade.

Também foram realizadas visitas técnicas para análise e aplicação dos indicadores no local de estudo, em maio de 2019.

O local de estudo se caracteriza como um balneário e pousada e tem sua atividade voltada para o ecoturismo e pesca esportiva. É um local já consolidado no município de Coxim (Figura 1). Atuante há aproximadamente 27 anos com atendimento ao turista. $O$ atrativo está localizado na zona rural de Coxim, tendo como via de acesso à rodovia 163, KM 751 sentido norte (Cuiabá), cerca de $25 \mathrm{Km}$ de distância do perímetro urbano do município.

Figura 1 - Mapa de localização da Cachoeira das Palmeiras, Coxim, MS

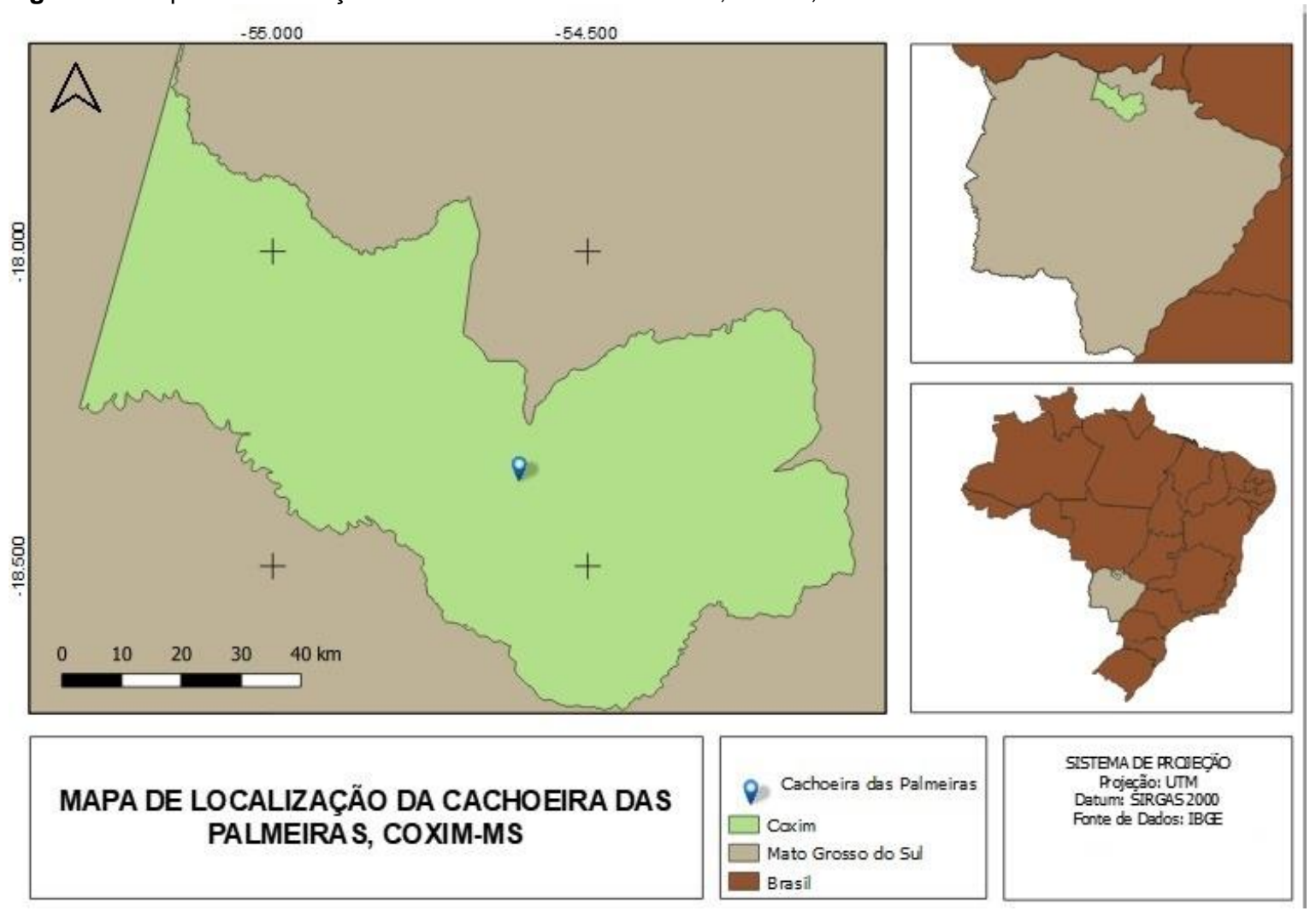

Fonte: Autoria Própria. 
O município de Coxim, de acordo com o último censo possui 32.159 habitantes e está localizado em meio a dois biomas diferentes o cerrado e o pantanal (IBGE, 2010). Por pertencer a esses dois biomas o município está localizado numa região diversificada em recursos naturais, favorecendo o desenvolvimento do turismo, e por muito tempo este município ficou conhecido como a cidade da pesca, devido a sua vastidão hídrica. No entanto, nos últimos tempos vêm despontando na região o Ecoturismo.

Os aspectos de textura do solo da área de estudo são de predomínio arenoso, típico dos solos do bioma Cerrado (GALDINO, 2012). De acordo com dados obtidos do IBGE (1990) o clima da região é do tipo sub-úmido a semi-ário, caracterizando-se por dois meses de excedentes hídricos geralmente entre novembro a janeiro e seis meses de deficiência hídrica geralmente de maio a setembro.

O empreendimento em estudo está localizado as margens do Rio Taquari. A Bacia Hidrográfica do Taquari, localizada na Região Centro Oeste do Brasil, é uma das principais drenagens formadoras da Alta Bacia do Rio Paraguai. Ela abrange a região de planaltos, também denominada Bacia do Alto Taquari e a Planície Pantaneira. A bacia tem como dreno principal o rio Taquari, cuja nascente localiza-se no estado do Mato Grosso, no município de Alto Taquari numa altitude de $860 \mathrm{~m}$ e, após percorrer $40 \mathrm{~km}$ nesse Estado, chega ao Estado de Mato Grosso do Sul (SOUZA et al., 2002).

\section{RESULTADOS E DISCUSSÃO}

Foram aplicados um total de 29 indicadores de sustentabilidade, 17 indicadores na dimensão ambiental, 6 indicadores na dimensão social e 6 indicadores para a dimensão econômica. Os indicadores utilizados para análise da atividade ecoturística podem ser observados no quadro 01 . 
Quadro 01 - Matriz de indicadores de impactos ambientais, sociais e econômicos e sua presença ou ausência na pousada estudada

\begin{tabular}{|c|c|c|c|}
\hline Dimensões & Indicadores & Descrição & $\begin{array}{l}\text { Presença/ } \\
\text { Ausência }\end{array}$ \\
\hline \multirow{15}{*}{ Ambiental } & Alteração da paisagem; & $\begin{array}{l}\text { Causada pela construção e operação da infraestrutura turística no } \\
\text { local; }\end{array}$ & Presença; \\
\hline & Presença de Fauna & Presença de animais silvestres no local. & Presença; \\
\hline & Pisoteamento da vegetação & Causados pela movimentação de pessoas nas trilhas; & Presença; \\
\hline & Alteração na qualidade do solo; & $\begin{array}{l}\text { Fatores que contribuem para a alteração das condições naturais do } \\
\text { solo como processos de compactação e erosão; }\end{array}$ & Presença; \\
\hline & Alteração na qualidade do ar; & $\begin{array}{l}\text { Fatores que contribuem para a alteração das condições } \\
\text { atmosféricas naturais: como a presença de queimadas e gases } \\
\text { liberados por veículos automotores; }\end{array}$ & Presença; \\
\hline & $\begin{array}{l}\text { Presença de caça e pesca no } \\
\text { local; }\end{array}$ & $\begin{array}{l}\text { Interferência no comportamento da fauna do local, tais como: } \\
\text { prejuízo para as espécies, cadeia alimentar, reprodução etc.; }\end{array}$ & Presença; \\
\hline & $\begin{array}{l}\text { Gestão de resíduos sólidos e } \\
\text { efluentes; }\end{array}$ & $\begin{array}{l}\text { Analisa se há tratamento e destinação final correta para os resíduos } \\
\text { sólidos produzidos no local; }\end{array}$ & Presença; \\
\hline & $\begin{array}{llll}\begin{array}{l}\text { Processos } \\
\text { reciclagem; }\end{array} & \text { e sistema } & \text { de } \\
\end{array}$ & $\begin{array}{l}\text { Presença de projetos de reciclagem dos resíduos sólidos } \\
\text { produzidos no local; }\end{array}$ & Presença; \\
\hline & Existência de compostagem & $\begin{array}{l}\text { Identifica se os restos de Resíduos Orgânicos estão sendo utilizado } \\
\text { para geração de material rico em húmus nutrientes e minerais. }\end{array}$ & Presença \\
\hline & Retirada da vegetação; & $\begin{array}{l}\text { Análise da supressão vegetal para construção da infraestrutura } \\
\text { local; }\end{array}$ & Presença; \\
\hline & Iniciativas de educação ambiental; & $\begin{array}{l}\text { Presença de projetos e programas que incentivem a educação } \\
\text { ambiental no local; }\end{array}$ & Presença; \\
\hline & $\begin{array}{l}\text { Presença de Regeneração } \\
\text { Natural; }\end{array}$ & Processo de regeneração natural da vegetação no local; & Presença; \\
\hline & $\begin{array}{lcc}\text { Presença } & \text { de } & \text { espécies } \\
\text { secundarias (Tardias) } & \end{array}$ & $\begin{array}{l}\text { Verificar a presença de espécies nativas em estágios avançados de } \\
\text { sucessão ecológica. }\end{array}$ & Presença \\
\hline & $\begin{array}{l}\text { Presença de Áreas verdes } \\
\text { preservadas }\end{array}$ & $\begin{array}{l}\text { Identificar a existência e a manutenção de áreas naturais protegidas } \\
\text { e preservadas. }\end{array}$ & Presença \\
\hline & $\begin{array}{l}\text { Processo de certificação } \\
\text { ambiental ou turística. }\end{array}$ & $\begin{array}{l}\text { Verificar se o estabelecimento apresenta Certificação ambiental ou } \\
\text { turística }\end{array}$ & Presença \\
\hline
\end{tabular}


Quadro 01 - Matriz de indicadores de impactos ambientais, sociais e econômicos e sua presença ou ausência na pousada estudada

\begin{tabular}{|c|c|c|c|}
\hline Dimensões & Indicadores & Descrição & $\begin{array}{l}\text { Presença/ } \\
\text { Ausência }\end{array}$ \\
\hline \multirow[b]{2}{*}{ Ambiental } & Licenciamento ambiental & $\begin{array}{l}\text { Verificar a autorização pelo órgão ambiental da operação de } \\
\text { empreendimentos }\end{array}$ & Presença \\
\hline & $\begin{array}{l}\text { Programas de minimização dos } \\
\text { impactos ambientais decorrentes } \\
\text { do turismo. }\end{array}$ & $\begin{array}{l}\text { Apresentar os cuidados a serem tomados para preservação da } \\
\text { qualidade ambiental. }\end{array}$ & Ausência \\
\hline \multirow{6}{*}{ Social } & $\begin{array}{l}\text { Presença de moradias e } \\
\text { moradores no local; }\end{array}$ & $\begin{array}{l}\text { Prevê a interferência cultural dos turistas no cotidiano dessas } \\
\text { pessoas; }\end{array}$ & Presença \\
\hline & Aumento da qualidade de vida; & Pela beleza cênica do local e uso recreativo; & Presença \\
\hline & $\begin{array}{l}\text { Capacitação dos funcionários do } \\
\text { local; }\end{array}$ & $\begin{array}{l}\text { Identificar se os funcionários são capacitados para a atividade } \\
\text { turística; }\end{array}$ & Ausência \\
\hline & Ações sociais & Realização de projetos sem fins lucrativos & Presença \\
\hline & $\begin{array}{l}\text { Satisfações com os serviços } \\
\text { oferecidos e verificação se os } \\
\text { turistas voltam outras vezes. }\end{array}$ & Identificar o aumento significativo de turistas durante os anos & Presença \\
\hline & Satisfação do turista; & $\begin{array}{l}\text { Satisfação do turista em relação ao infraestrutura e hospedagem do } \\
\text { local; }\end{array}$ & Presença \\
\hline \multirow{6}{*}{ Econômico } & Geração de renda; & Causada pela prestação de bens e serviços no local; & Presença \\
\hline & Geração de emprego; & Causada pela prestação de bens e serviços no local; & Presença \\
\hline & $\begin{array}{l}\text { Recursos financeiros gastos pelos } \\
\text { turistas. }\end{array}$ & $\begin{array}{l}\text { Caracteriza os lucros econômicos gerados pelas atividades } \\
\text { oferecidas no local. }\end{array}$ & Presença \\
\hline & $\begin{array}{l}\text { A oferta de hospedagem é } \\
\text { suficiente para atender à } \\
\text { demanda Turística. }\end{array}$ & $\begin{array}{l}\text { Identificar a disponibilidade de funcionamento do estabelecimento } \\
\text { turístico para atendimento à demanda de turistas }\end{array}$ & Presença \\
\hline & Presença de atrativos turísticos & $\begin{array}{l}\text { Presença de recursos naturais ou culturais necessários para o } \\
\text { incentivo a visitação }\end{array}$ & \\
\hline & Sazonalidade Turística & Identificar as temporadas turísticas & Presença \\
\hline
\end{tabular}

Fonte: Os autores 
Para a dimensão ambiental dos dezessete indicadores utilizados apenas um esteve ausente.

Verificou-se a alteração da paisagem pela construção e operação da infraestrutura turística do local, composta de moradias, dormitórios e restaurantes, além de trilhas e estacionamentos. Pires (1993) relata que a paisagem possui como característica a fragilidade, que pode ser vista como um nível de exposição à modificação negativa causada por atividades e processos humanos. Se relacionado a atividade do ecoturismo, fica evidente que quanto mais atrativa a paisagem maior seu grau de fragilidade e risco de degradação. Porém, pode ser destacado a inevitabilidade da alteração do ambiente, bem com sua estrutura paisagística quando qualquer atividade é implantada no local.

Também foi possível observar no local de estudo, a presença de animais silvestres. Como o local se caracteriza como uma área de mata fechada e com um ambiente natural, a presença de animais silvestres, como macacos, cachorros-do-mato, gambás, e pássaros diversos é considerada comum, o balneário também explora a potencialidade do local para receber turistas interessados na observação da natureza. Na Figura 2, é possível visualizar um representante dessa fauna silvestre, uma imagem capturada no local de estudo.

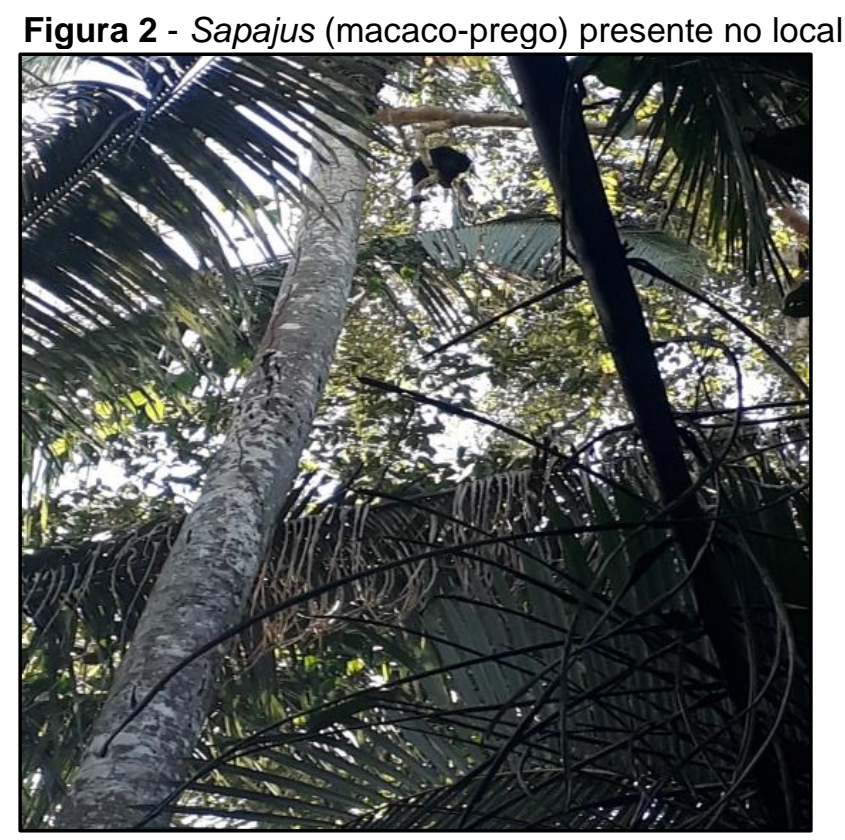

Fonte: Os autores

No entanto evidenciou-se no local o pisoteamento da vegetação e a compactação do solo, ocasionado pelo uso das trilhas em meio ao ambiente florestal, alterando a qualidade ambiental desse ambiente (Figura 3). De acordo com Figueiredo et al., 2010, essa compactação do solo é um dos principais impactos causados pelo turismo, e podem 
resultar em consequências maiores como a erosão e assoreamento de corpos hídricos.

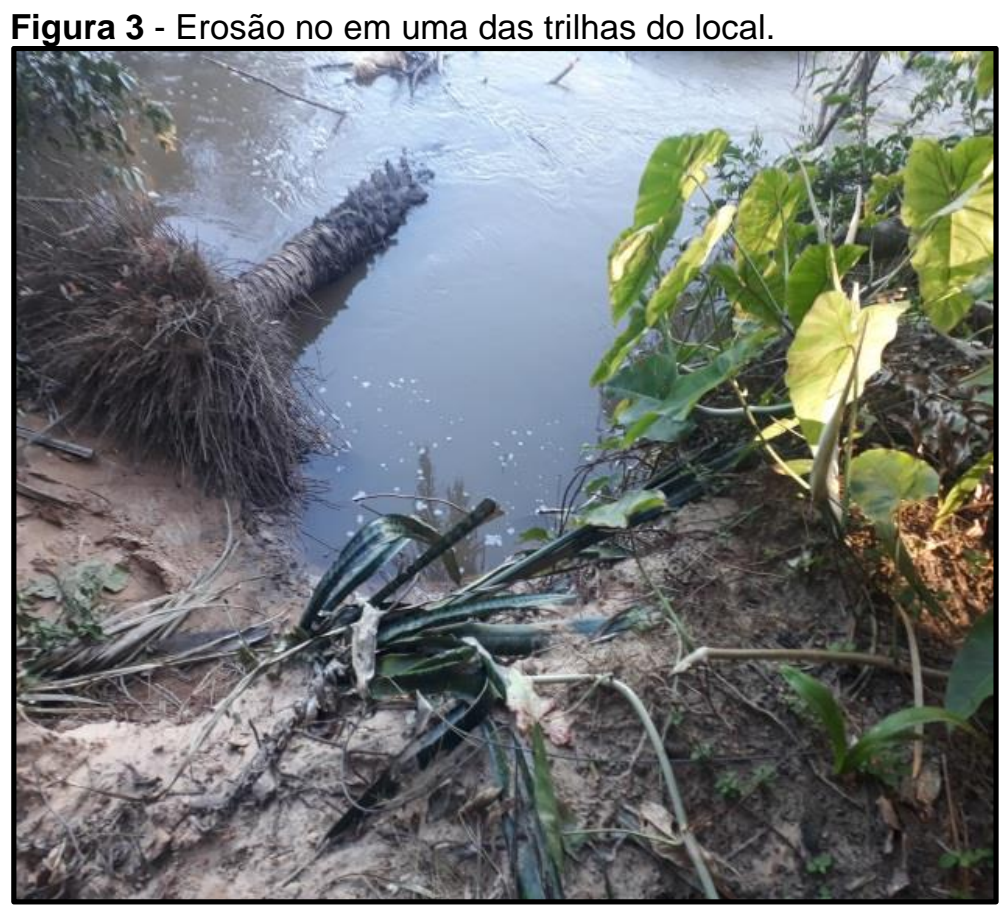

Fonte: Os autores.

A Alteração na qualidade do ar, também aplicada como indicador ambiental, foi verificada no local, porém gerada apenas pela queima de gases liberados por veículos automotores.

Quanto a interferência no comportamento da fauna do local, tais como: prejuízo para as espécies, cadeia alimentar, reprodução etc. pela presença de caça e pesca, verifica-se a atividade de pesca esportiva como uma das principais atrações, no entanto, não se tem noção do grau de interferência humana no comportamento da ictiofauna local, de modo que, apenas o emprego de estudos científicos na área confirmará se a atividade interfere na quantidade de peixes do corpo hídrico.

Em relação ao indicador gestão de resíduos sólidos e efluentes produzidos no local, foi identificada sua coleta, destinação temporária e final adequada, já que os resíduos sólidos são separados e depositados em local fechado e posteriormente recolhidos para aterro controlado pela prefeitura municipal e os efluentes são destinados para fossas sépticas.

Em relação a procedimentos de reciclagem realizados dentro do empreendimento, observou-se a reciclagem de resíduos orgânicos em composteiras e a venda de materiais de alumínio para fábricas de reciclagem.

A geração de resíduos sólidos, quando descontrolada e mal gerenciada, é uma 
ferramenta que pode provocar problemas nos âmbitos ambientais e sociais, por isso o manejo adequado destes resíduos é fundamental nas instituições privadas, sociedade civil e organizações não governamentais. Segundo Ribeiro et al. (2010) o indicador de Resíduos Sólidos tem por objetivo analisar a geração e o manejo dos resíduos sólidos dentro do estabelecimento, pois é de extrema necessidade a reavaliação do tratamento e destino em alternativas como a reciclagem.

A retirada da vegetação no local de estudo se dá pela construção das moradias, restaurantes, do estacionamento e áreas de lazer, pois como já citado, é inevitável o impacto ambiental em qualquer área em que um empreendimento seja implantado. Em contrapartida verificaram-se esforços para manutenção da vegetação nativa, por meio da observação da avifauna e trilhas contemplativas da vegetação. O ecoturismo é composto de dois principais fatores o nível de qualidade ambiental do determinado lugar, caracterizado principalmente pela preservação da natureza e do alcance de um ambiente mais natural possível, e o nível de satisfação do turista que depende inteiramente dessa qualidade ambiental e da infraestrutura local (EAGLES, 2001).

Verificou-se a existência de iniciativas de educação ambiental por meio de placas de sinalização educativas acerca da preservação e do cuidado com a natureza (Figura 4). O local também realiza o recebimento de grupos escolares e universitários de forma gratuita, visando a educação ambiental a partir da visitação e pesquisa científica. A atividade ecoturística deve ser composta de diferentes componentes que se complementam, como o econômico, ecológico, cultural, social e educacional, onde a educação e a conscientização ambiental devem ser as bases para o desenvolvimento de um turismo sustentável (BUENO e PIRES, 2006).

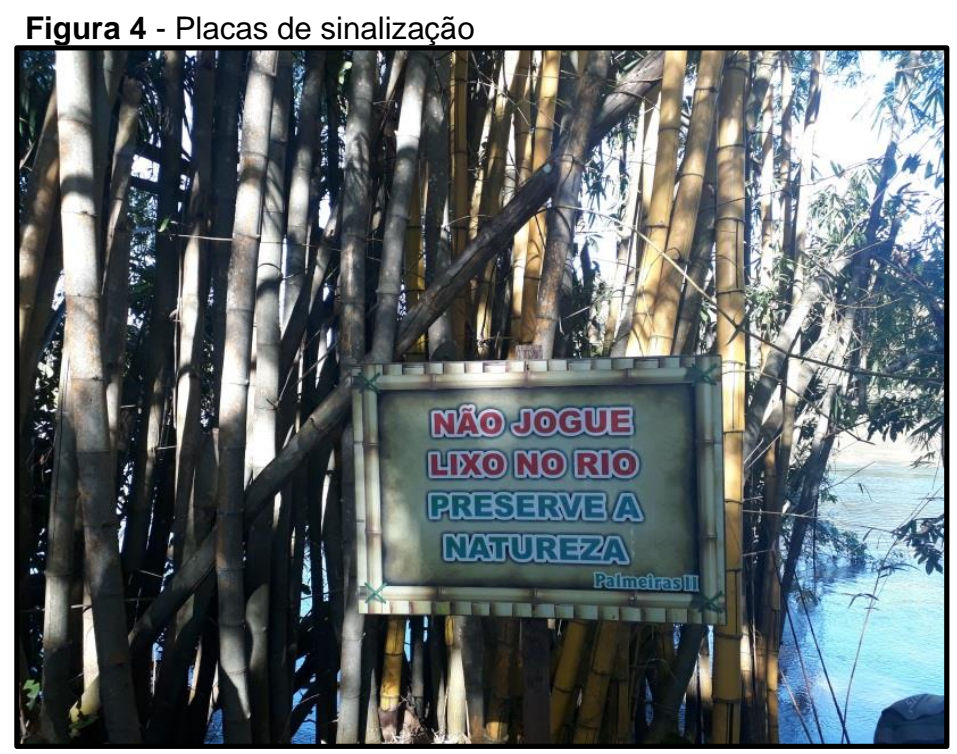

Fonte: Os autores. 
Segundo Rigonat (2002), a educação ambiental, é um ramo da educação cujo objetivo é a disseminação do conhecimento sobre o meio ambiente, a fim de ajudar à sua preservação e utilização sustentável dos seus recursos.

Quanto a ocorrência de regeneração natural constatou-se que no local de estudo ocorre um forte processo natural de regeneração, pela presença de espécies arbóreas nativas, inclusive com estágio secundário ou tardio de sucessão, como por exemplo o Bacuri (Platonia insignis), o Buriti (Mauritia flexuosae), Barbatimão (Stryphnodendron adstringens), Ipê- Amarelo (Handroanthus albus), Bocaíuva (Acrocomia aculeata) entre outras, além da presença de serrapilheira no solo, características fundamentais para a recuperação de áreas impactadas e reconstituição da vegetação natural.

Como o local está localizado as margens do rio Taquari, possui áreas verdes preservadas. De acordo com Souza (2010), a presença de áreas verdes constitui em importante ferramenta para a regulação do clima, manutenção da biodiversidade, além dos aspectos paisagísticos, de lazer e recreativos, assim como servem de parâmetro para avaliar a qualidade de vida social (Figura $5 a$ e $5 b$ ).

Figura 5a- Área verde de Preservação Ambiental Figura 5b - Rio Taquari.

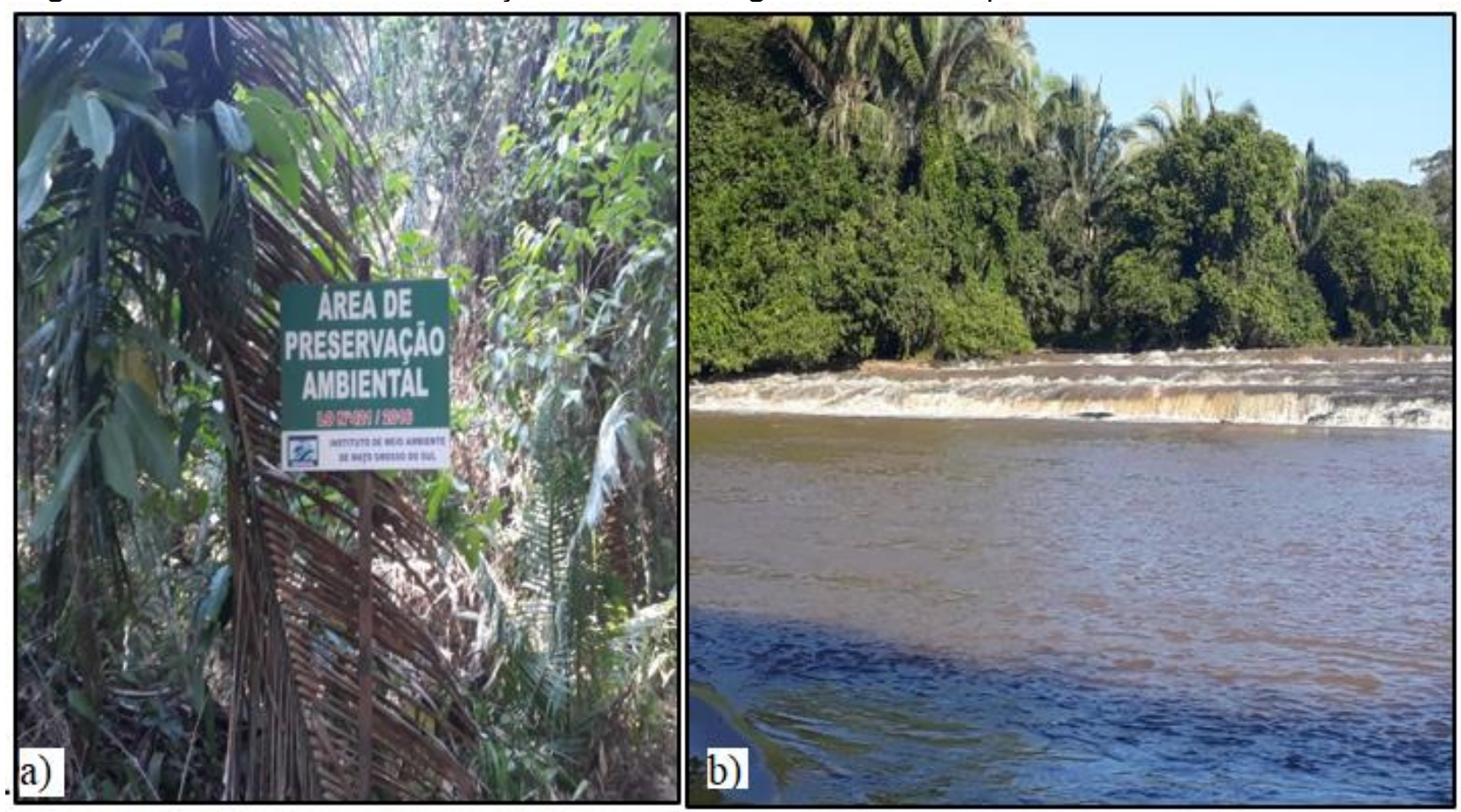

Fonte: Os autores.

O empreendimento possui certificação pelo Cadastur e licença de operação. Segundo Hanai (2009) a certificação é concedida aos empreendimentos que nos processos de seus produtos ou serviços respeitam os dispositivos legais referentes ás questões 
ambientais, o certificado Cadastur é um sistema de cadastro de pessoas físicas e jurídicas que atuam no setor de turismo garantindo diversas vantagens e oportunidades aos seus cadastrados e é também uma importante fonte de consulta para o turista. A licença de operação, autoriza a operação da atividade ou do empreendimento, após verificar o cumprimento do que consta nas licenças anteriores, com as medidas de controle ambiental e as condições determinadas para a operação.

O indicador de programa de minimização dos impactos ambientais decorrentes do turismo foi o único indicador ausente na dimensão ambiental.

Quanto a dimensão social: Foram seis indicadores aplicados quanto a esta dimensão, dos quais apenas um foi ausente.

Verificou-se a presença de trabalhadores que residem no local. Ressalta-se a interferência dos turistas no cotidiano desses moradores, principalmente em relação à privacidade e insegurança, porém, existe um aumento da qualidade de vida, até mesmo relatado pelos moradores, por residirem no próprio local de trabalho e não arcarem com custos de transporte ou aluguel, por exemplo, além de poder contemplar no ambiente de trabalho um local em constante contato com a natureza, harmônico e livre de poluições e contaminações dos grandes centros urbanos.

O local não conta com capacitação dos funcionários para o recebimento dos turistas, Beverly (et al, 2015) relata que a função do guia de turismo e dos trabalhadores no ramo são essencialmente a orientação e transmissão das informações do local turístico e da cultura tradicional aos visitantes. Desse modo, entende-se como um fator principal para o desenvolvimento da atividade turística essa capacitação dos funcionários do empreendimento.

Em relação as ações socias, o local costuma receber gratuitamente entidades e instituições para visitação tais como universidades, escolas e instituições sociais.

Não existe no local uma forma de mensurar a qualidade do atendimento ou a satisfação do turista, no entanto os administradores mencionam, o aumento do público que passaram a receber nos últimos anos, o que pode ser um indicador da qualidade desses serviços. Este fator pode interferir diretamente no crescimento e desenvolvimento do empreendimento, pois essa satisfação é o principal item para o retorno do visitante ao ponto turístico e sua divulgação para parentes e amigos que induzem consequentemente 0 desenvolvimento do local (FERREIRA e STAUB, 2014).

Para a dimensão econômica: foram delimitados seis indicadores para aplicar-se ao presente estudo, os quais se demonstraram presentes. 
A atividade de ecoturismo e pesca esportiva geram renda com o comércio de bens e serviços entre funcionários e turistas do empreendimento. O que consequentemente gera também empregos para os moradores locais, que se destaca como outro indicador econômico. Fagundes e Ashton (2010) ressaltam que o turismo e todas as suas classificações se caracterizam como geradores de emprego, renda e desenvolvimento socioeconômico.

A respeito dos atrativos turísticos existentes no local, como vemos na Figura 6 , a cachoeira das palmeiras é o principal, seguido da pesca esportiva e da apreciação da natureza. Segundo Burti (2016), atrativos turísticos se conceituam como recursos naturais ou culturais que são necessários para comercialização, recepção, incentivo e promoção do turismo, de modo a ser o item principal de atração desses consumidores. Desse modo, a pousada é conhecida principalmente pelo contato com a natureza e sua riqueza ambiental, sendo esses indicadores de incentivo ao ecoturismo e a preservação da natureza.

Figura 6 - Cachoeira das Palmeiras, principal atrativo natural da pousada

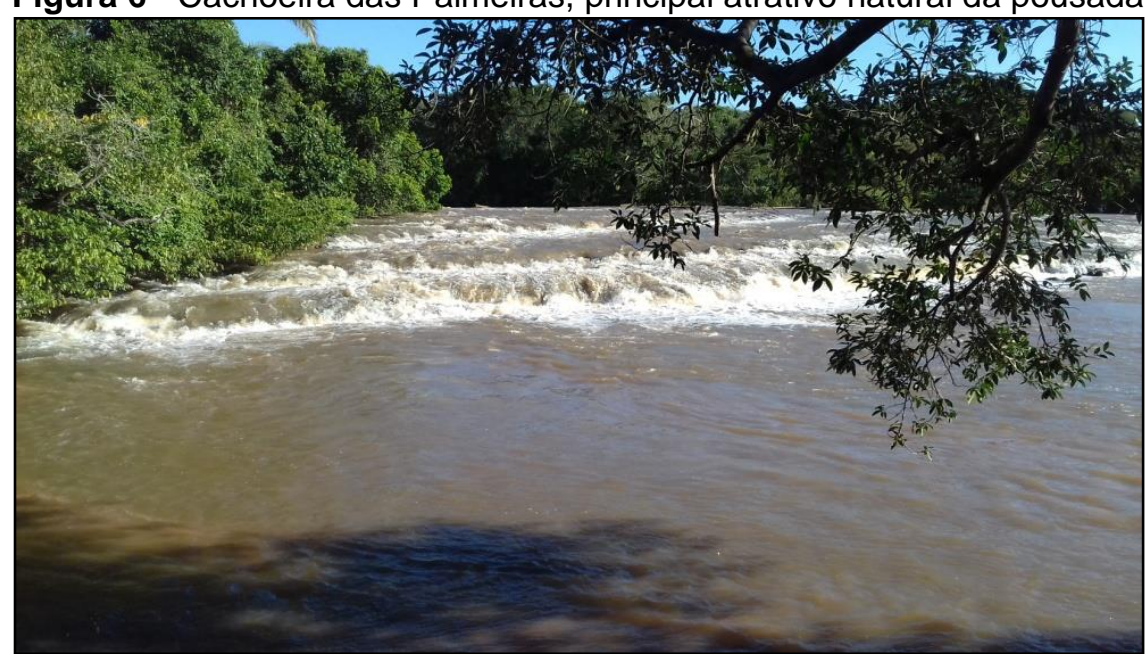

Fonte: Os autores.

Segundo Butler (1994) o indicador de sazonalidade é uma característica pertinente ao setor turístico, considerada como um desequilíbrio temporal no fenômeno turístico, que pode ser expresso em termos de dimensões tais como: número de visitantes, despesas de visitantes, tráfego nas estradas e em outras formas de transporte, emprego e ingressos em atrações. Esse indicador identifica o número de turistas durante o ano caracterizando-se pela baixa, média e alta temporada. De acordo com Mota (2001) os principais efeitos da sazonalidade são: desemprego, queda do faturamento das empresas turísticas, que provoca o comprometimento da qualidade do atendimento. O local de estudo assim como 
a maioria dos locais turísticos também enfrenta sazonalidades, geralmente este local passa por um declínio do público, relacionado a pesca esportiva, entre outubro e janeiro, épocas de piracema, no entanto como o local também é destino de banhistas e apreciadores do ecoturismo, o local recebe nesta época turistas em férias com a família, por exemplo. E como está localizado em uma região de temperaturas elevadas durante todo o ano, o local está sempre propício a visitação.

\section{CONCLUSÃO}

A atividade ecoturística em uma pousada no município de Coxim, MS, se analisada por meio de indicadores ambientais, sociais e econômicos se destaca como uma atividade que possui impactos moderados ao meio ambiente e ao meio social e impactos positivos ao meio econômico, pois utiliza métodos de baixo impacto ambiental e induz o desenvolvimento econômico e social.

Conclui-se que o planejamento adequado do turismo tem sido uma importante ferramenta para o alcance do desenvolvimento sustentável, pois o mesmo busca equilibrar o crescimento econômico, como as necessidades da população e com a capacidade de regeneração dos recursos naturais, ou seja, busca atentar as necessidades do homem sem modificar totalmente o meio ambiente.

Um sistema de indicadores de sustentabilidade, promove informações importantes que podem estimular a compreensão dos problemas econômicos, sociais e ambientais, assim como facilitar a capacidade da comunidade em criar e conduzir políticas e projetos e programas como uma alternativa para operacionalizar o desenvolvimento sustentável.

\section{REFERÊNCIAS}

BENI, M. C. Análise estrutural do turismo. São Paulo: Editora SENAC, 2002.

BEVERLY, D.; MELO, B. G. E RAPÉ L. S. A importânçia da qualificação profissional do guia de turismo na tríplice fronteira: Um estudo de caso. In: FÓRUM INTERNACIONAL DE TURISMO DO IGUAÇU, 9., 2015. Anais.......]. Foz do Iguaçu, PR. 2015.

BRAGA, D. C. Planejamento turístico: teoria e prática. Rio de Janeiro: Elsevier, 2007.

BUENO, P. F. E PIRES, S. P. Ecoturismo e educação ambiental: possibilidades e potencialidades de conservação da natureza. In: SEMINTUR - SEMINÁRIO DE PESQUISA EM TURISMO DO MERCOSUL, 4. 2006. Anais [...]. Caxias do Sul, RS, 2006.

BURTI A. Entendendo o atrativo turístico. São Paulo: Sebrae, 2016. 
BUTLER, R. Issues in applying carrying capacity concepts: examples from United Kigdom. In: COCCOSSIS, H. MEXA, A. Planning and management for tourism growth is becoming essential in the context of sustainable development. 1. ed. 2004, cap. 7 p. 135-150, 1994.

DUTRA, C. V.; SLINDER, S. F.; ROCHA, M. R. A.; MARTINS S. G. E FERREIRA A. C. M. Indicadores do turismo sustentável: uma proposta de monitoramento turístico para o parque estadual do Jalapão, TO.Tocantins: Instituto Federal do Tocantins, 2015.

EAGLES, P. F. J. International trends in park tourism. Europarc 2001, Edition 4, Matrei, 43 pp. 2001.

FADINI, B. A. A.; HOEFDEL, M. L. J.; SUAREZ, S. F. C.; CAPODEFERRO G. E. E FERMINO S. E. Indicadores de turismo sustentável para áreas naturais de vargem. São Paulo, Brasil, 2010.

FAGUNDES, C. E ASHTON, G. S., desenvolvimento regional através do turismo: geração de emprego e renda. Semintur Jr. Caxias do Sul, RS, 2010.

FERREIRA, B. T. E STAUB A. Estudo sobre a satisfação do turista que visita o município de Rio Pardo durante o evento da semana santa, 2014.

FIGUEIREDO, A. M.; BRITO A. Í.; TAKEUCHI, C. R.; ANDRADE A. M. E ROCHA V. T. C. Compactação do Solo como Indicador Pedogeomorfológico para Erosão em Trilhas de Unidade de Conservação: estudo de caso no Parque Nacional da Serra do Cipó, MG. In: SIMPÓSIO NACIONAL DE PEDOGEOMORFOLÓGIA. Anais [...] Diamantina, MG. 2010. Disponível em: http://lsie.unb.br/ugb/sinageo/8/6/5.pdf. Acesso em: 20 maio 2019.

GALDINO, S. Estimativa da perda de terra sob pastagens cultivadas em solos arenosos da bacia hidrográfica do Alto Taquari MS/MT. Tese (Doutorado) - Universidade Estadual de Campinas. Campinas, SP, 2012.

HANAI, F. Y. Sistema de indicadores de sustentabilidade: uma aplicação ao contexto de desenvolvimento do turismo na região de bueno brandão Estado de Minas Gerais, Brasil. Tese (Doutorado) - Universidade Federal de São Carlos - Escola de Engenharia de São Carlos, São Paulo, 2009.

IBGE. Instituto Brasileiro de Geografia e Estatística. Censo demográfico: referencial do estado de Mato Grosso do Sul. Brasília: IBGE, 2010.

IBGE. Instituto Brasileiro de Geografia e Estatística. Mapa multi: referencial do estado de Mato Grosso do Sul. Brasília: IBGE, 1990.

IGNARRA, L. R. Fundamentos do turismo. São Paulo: Pioneira, 1999.

LACERDA, C. DE S. Sistema de indicadores de sustentabilidade para atividade turística: Uma proposta metodológica participativa aplicada no município do Conde/PB. Dissertação (Mestrado) - Programa de Pós-Graduação em Recursos Naturais - Universidade Federal de Campina Grande, Campina Grande, 2011.

MMA - MINISTERIO DO TURISMO. Ecoturismo: orientações básicas. 2. ed. Brasília. p.90, 2010.

MOTA, K. C. N. Marketing turístico: promovendo uma atividade Sazonal. São Paulo: Atlas, 2001. NUNES R. E., MARTINS F. M. Indicadores de sustentabilidade para o turismo sustentável: um estudo no município de Bananeiras-PB. EMGEMA. 2019.

https://doi.org/10.34024/rbecotur.2019.v12.6728. 
OLIVEIRA, S. E. Impactos socioambientais e econômicos do turismo e suas repercussões no desenvolvimento local: o caso de Itacaré - Bahia. Tese (Mestrado em cultura e turismo). Universidade Estadual de Santa Cruz, Universidade Federal da Bahia. Ilhéus, Bahia, p. 153, 2008. https://doi.org/10.1590/S1518-70122007000200006

ORGANIZAÇÃO MUNDIAL DE TURISMO - OMT. Introducción al turismo. Madri, 1998.

PARRIS, T.M. E KATES, R.W. Caracterizing and measuring sustainable development. Annu: Reviews in advance, v. 28, p. 1-13, 2003.https://doi.org/10.1146/annurev.energy.28.050302.105551

PIRES, P. dos S. Procedimentos para análise da paisagem na avaliação de impactos ambientais. In: Manual de avaliação de impactos ambientais - MAIA. 2. ed. Curitiba: PIAB, 1993.

REED, J.S.; FRASER, E.D.G. E DOUGILL, A. J. An adaptative learning process for developing and applying sustainability indicators with local communities. Ecological Economics, v. 59, p.406418, oct. 2006. https://doi.org/10.1016/j.ecolecon.2005.11.008

REZENDE F. C., REZENDE C. D. Impactos do turismo: uma análise sob a ótica da população receptora. 2005. Disponível em: http://www.anpad.org.br/admin/pdf/enanpad2005-apsc-2576.pdf. Acesso em: 14 maio 2019.

RIBEIRO, F. S.; CARMO, J.; MARQUES, R. M. B. S. E FERREIRA JR. H. Os possíveis impactos ambientais causados pelo aumento do lixo rural. Relatório para a Escola Politécnica da Universidade de São Paulo - USP. Instituto de Energia e Eletrotécnica da Universidade de São Paulo - IEE-USP, 2010.

RIGONAT, M. C. Hacia una educación ambiental anclada en el local. Revista Gestão em Ação, Salvador, v. 5, n. 2, p. 127-144, 2002.

Rodrigues, A. B. Turismo: desenvolvimento local. São Paulo: Hucitec, 1999.

RUSCHMANN, D. V. de M (Editores). Gestão ambiental e sustentabilidade no turismo. Barueri SP: Manole, 2010. (Coleção Ambiental, v. 9).

SILVA C. N., CÂNDIDO A. G., Sistema de indicadores de sustentabilidade do desenvolvimento do turismo: um estudo de caso do município de Areia - PB. Revista Brasileira Pesquisa em Turismo. São Paulo, v. 10, n. 3, p. 475-496, set./dez. 2016. https://doi.org/10.7784/rbtur.v10i3.955

SOUZA, L. A. P. D., PORSANI, J. L., SOUZA, O. C. D., E MOUTINHO, L. Levantamento experimental GPR no Rio Taquari, Bacia do Pantanal Matogrossense. Revista Brasileira de Geofísica, v. 20, n. 1, p. 67-72, 2002. https://doi.org/10.1590/S0102-261X2002000100006

SOUZA, R. R. Áreas verdes e urbanismo. Universidade Federal de Lavras, 2010. Disponível em: http://www.prpg.ufla.br/ppg/fitotecnia/_adm/upload/file/\%C3\%81RE AS+VERDES+E+URBANISM O[1]\%20[Modo\%20de\%20Compatibilidade].pdf. Acesso: maio 2019.

TOFANI, F. P. Os desafios do desenvolvimento sustentável em comunidades frágeis sob o impacto do turismo. Revista EA, Belo Horizonte, p. 2-25, mar. 1999.

VAN BELLEN, H. M. Indicadores de sustentabilidade: uma análise comparativa. Tese (Doutorado em Engenharia de Produção) - Programa de Pós-Graduação em Engenharia de Produção. (2006). Universidade Federal de Santa Catarina, 235 p. 2006. 